\title{
Lendo entrelinhas e rodapés: aspectos de gênero em pesquisas com crianças sobre as mídias
}

\author{
Gilka Elvira Ponzi Girardello
}

\section{Resumo}

Este artigo examina um conjunto de pesquisas brasileiras sobre as mídias na vida das crianças, colocando em primeiro plano aspectos de gênero que eram secundários na maioria dos trabalhos. Encontram-se ali registros de pesquisas de campo principalmente falas de crianças - realizadas entre 2000 e 2010 no contexto de um grupo sediado na Universidade Federal de Santa Catarina. Tais pesquisas basearam-se nos estudos culturais, nos estudos de recepção latino-americanos e nos estudos da infância contemporâneos. Desse quadro teórico-metodológico fazem parte discussões sobre as relaçôes de gênero na pesquisa com crianças sobre as mídias, cujos aspectos principais são sintetizados no trabalho, a partir, principalmente, de Joseph Tobin e David Buckingham. Das falas das crianças registradas e analisadas nas pesquisas, e selecionadas no âmbito do presente trabalho, conclui-se que, se muitas vezes as crianças encenam e reproduzem preconceitos, elas são também capazes de identificar na cultura das mídias elementos problemáticos do ponto de vista de gênero, que provocam desconforto, desigualdade e exclusão; que as situaçóes de pesquisa em que as crianças se manifestam sobre sua experiência com as mídias podem ser um espaço importante de negociação e resistência; que a crítica às representaçôes de gênero dualistas e estereotipadas nas mídias permanece sendo muito importante no século XXI. Com base na discussão, reafirma-se a importância dos projetos voltados a uma educação inclusiva, não sexista e anti-homofóbica.

Palavras-chave: Gênero. Mídias. Criança.

* Doutora em Ciências da Comunicação pela Universidade de São Paulo (USP). Professora do curso de Pedagogia e do Programa de Pós-Graduação em Educação na Universidade Federal de Santa Catarina (UFSC). 


\section{Introdução}

Este artigo examina um conjunto de pesquisas brasileiras sobre as mídias na vida das crianças, buscando enfatizar os aspectos de gênero implícitos nelas ou sugeridos por elas. Diante da persistência de representaçôes problemáticas de gênero e diversidade sexual no discurso midiático, agravada pelo retrocesso conservador que se verifica nesse campo nos últimos anos, avaliamos que o tema precisa ser objeto de uma atenção renovada dos pesquisadores da relação entre mídia e infância ${ }^{1}$. Para contribuir com esse esforço, voltamos nosso olhar para esse conjunto de pesquisas, buscando valorizar o que nelas as crianças dizem sobre gênero, bem como lançar luz sobre os aspectos de gênero presentes em sua fundamentação teórico-metodológica, que até agora permaneciam na sombra.

As pesquisas foram realizadas de 2000 a 2010 no âmbito de um grupo sediado na Universidade Federal de Santa Catarina ${ }^{2}$ (UFSC), ao qual pertencemos, e têm em comum um quadro de referências teóricas e abordagens metodológicas que incluem a escuta das vozes das crianças, em diferentes situaçôes e contextos. Ainda que gênero não seja uma categoria central da maioria desses trabalhos, avaliamos que o conjunto de evidências empíricas produzidas nesse contexto - toda uma riqueza de falas de crianças sobre sua vida com as mídias - mereça atenção desde uma perspectiva de gênero, e este foi um primeiro objetivo do trabalho. Afinal, diversas vezes as autoras desses trabalhos mencionam cenas e exemplos trazidos do campo de pesquisa, sugerindo que eles poderiam ser analisados em termos de gênero, mas que isso fugiria ao foco específico do trabalho. Como gênero náo é sequer uma das palavras-chave da maioria dos trabalhos, avaliamos que tais falas e cenas dificilmente seriam localizadas por outros/as pesquisadores/as interessados/as em gênero, e assim deixariam de contribuir para a discussão do tema entre nós.

Além disso, entendemos que há muito em comum entre as bases teóricoepistemológicas da tradição de pesquisas com crianças sobre as mídias que desenvolvemos no grupo e as de muitas pesquisas de gênero, especificamente aquelas com foco nas crianças. Explicitar tais pontos em comum, fazer aflorar os pressupostos e subentendidos a respeito de gênero nas pesquisas sobre mídias e crianças que temos acompanhado foi um segundo objetivo deste trabalho.

Um terceiro objetivo foi buscar contribuir para a discussão sobre gênero nos debates sobre infância e mídias, compartilhando e dando visibilidade às referências a gênero já presentes na obra de alguns/as autores/as que compóem nosso quadro teóricometodológico, e que talvez ainda possam ser melhor apropriadas e problematizadas em nosso campo de estudos, de modo a permitir que em futuras pesquisas as reflexôes sobre 
o tema possam ser mais iluminadoras e não se limitem à notas de rodapé. Este artigo, assim, representa um esforço de balanço não desprovido de motivação crítica (e autocrítica), que esperamos poder interessar também a outros/as colegas que têm se dedicado ao estudo da presença das mídias no cotidiano das crianças, no sentido de contribuir para uma educação mais igualitária.

\section{Pesquisas com crianças sobre as mídias}

Nossas pesquisas inicialmente se apoiaram na vertente de estudos sobre a relação das crianças com as mídias que, a partir da década de 1980, baseou-se nos estudos culturais, nas análises do discurso e na semiótica. Fazemos parte de uma geraçáo de pesquisadores/as brasileiros/as que, na década de 1990, contribuiu para a criação de uma corrente de estudos de recepção de mídia com crianças no país. Em nosso grupo, incorporamos também as referências de autores que, na Inglaterra, na Austrália, nos Estados Unidos e no Havaí, vinham pesquisando intensamente a interação das crianças com as mídias. A premissa central desse quadro de referências são os poderes semióticos das crianças e a complexidade dos significados que elas constroem, exemplificada na atenção dada pelos australianos Bob Hodge e David Tripp (1986), em sua obra seminal Children and Television: a semiotic approach, à produção de sentido realizada pelas crianças durante e após a audiência aos programas de televisão.

Nessa mesma vertente, outro autor que foi central para nossos projetos é o inglês David Buckingham, um dos mais férteis investigadores da fala das crianças sobre a televisão. Buckingham realizou pesquisas empíricas por mais de 25 anos sobre a relação da criança com as mídias, a partir de uma confluência teórica entre os estudos da cultura, da comunicação e das sociedades. Em seus trabalhos pioneiros de escuta e diálogo com crianças sobre sua recepção de televisão (BUCKINGHAM, 1991, 1993), a principal diretriz metodológica pode ser resumida nesta frase: "Nem o significado do texto nem o das posiçóes sociais das crianças são inteiramente dados: embora com limitaçôes, ambos são estabelecidos e negociados simultaneamente através da conversa" ${ }^{3}$ (BUCKINGHAM, 1993, p. 59, grifo nosso).

Naquelas obras, o autor saudava a visão da criança como espectadora ativa e sofisticada, que teria, na pesquisa qualitativa de recepção, substituído a visão da criança submissa e passiva diante das influências da televisão, consideradas quase sempre como daninhas. Ao mesmo tempo, porém, ele sugeria cautela crítica para que não caíssemos no problema inverso, que seria o de, em vez da imagem tradicional da criança inocente e vulnerável, concebermos a "imagem igualmente romântica da criança sábia e liberada". Desse modo, diz ele, "estaríamos continuando a falar da 'criança' enquanto uma categoria universal, em vez de falar sobre crianças específicas vivendo em contextos sociais e históricos específicos" (BUCKINGHAM, 1991, p. 228). 
A partir de contribuiçóes da sociologia da infância, da etnografia e dos estudos feministas, Buckingham (1991) enfatizava já nesses seus primeiros trabalhos a importância das dinâmicas interpessoais e a dimensão de performance subjetiva e construção identitária que entra em jogo nas situaçóes de pesquisa com crianças, tais como entrevistas e grupos de discussão. Destacava o quanto, ao falar, as crianças estão definindo a si próprias e aos companheiros, usando implicitamente categorias como idade, classe, etnicidade e também gênero. $\mathrm{Na}$ esteira da reflexão teórico-metodológica de Buckingham, outro autor que muito inspirou as pesquisas sobre a mídia na vida das crianças em nosso contexto foi o pesquisador havaiano Joseph Tobin (2000), cujo trabalho, também com grande vigor empírico, é marcado por preocupaçóes com os aspectos ligados a classe social, gênero e poder presentes na fala das crianças em situaçōes de pesquisa. No âmbito deste artigo, é a discussão específica sobre gênero o que mais nos interessa na obra desses dois pesquisadores.

A partir de referências como essas, a partir da década de 1990 em nosso grupo fomos desenvolvendo pesquisas com crianças sobre sua experiência com as mídias, por meio de procedimentos empíricos na região de Florianópolis. Temos estudado a relação das crianças com a televisão, com o cinema, com o jornalismo, com a internet, com videogames e diversos outros aspectos da cultura digital, sempre buscando contribuir para a uma articulaçáo mais qualificada entre educação, arte e cultura. O recorte aqui privilegiado abarca seis pesquisas de campo com crianças sobre mídias realizadas no grupo entre 2000 e 2010. Embora um número bem maior de pesquisas tenham sido realizadas no contexto do grupo, incluindo diversas teses de doutorado, optamos por privilegiar aqui alguns trabalhos de conclusão de curso, iniciação científica e mestrado, justamente para dar atençáo e visibilidade ao que se produz, senão às margens, pelo menos em recantos fora do centro mais iluminado do palco acadêmico.

Embora apenas um desses seis trabalhos tivesse a categoria gênero como central, todos eles produziram relatos de falas de crianças que podem ajudar a compreender o papel das inflexốes de gênero na constituiçáo subjetiva de grupos de crianças nos contextos de pesquisa, e particularmente em seus atravessamentos pelo imaginário midiático. Iremos retomar e refletir sobre alguns desses registros mais adiante, depois de apresentar uma síntese das referências em que temos nos embasado - exemplificadas aqui a partir de Buckingham $(1991,1993)$ e Tobin (2000) - para as pesquisas de escuta das crianças sobre suas experiências com as mídias. O foco dessa síntese será o modo como a categoria gênero aparece nesse contexto teórico-metodológico e, consequentemente, nos trabalhos posteriores de nosso grupo, ainda que muitas vezes apenas de modo implícito, nas entrelinhas. 


\section{Gênero no horizonte teórico-metodológico das pesquisas sobre crianças e mídias}

Uma das referências teórico-metodológicas iniciais mais úteis para as pesquisas de nosso grupo foi o livro Children Talking Television, de Buckingham (1993). Ele se baseia em uma pesquisa de recepção de televisão realizada com 90 crianças ao longo de um ano e meio, em grupos focais em diferentes escolas públicas de Londres em 1986. Como sugere o título, "a pesquisa preocupou-se centralmente com os modos como as crianças de 7 a 9 anos falam sobre televisão" (BUCKINGHAM, 1993, p. 34, grifo nosso). Em diálogo com a perspectiva dos estudos culturais, o autor enfatiza a importância da atenção aos contextos sociais e culturais dessa produção discursiva, em que gênero tem um importante papel, assim como classe social e etnicidade.

Com relação a gênero, um primeiro cuidado se evidencia na composição dos grupos focais de crianças, inclusive em relação ao pesquisador: as crianças foram agrupadas em diferentes combinaçóes ao longo dos 15 meses em que se realizadas as muitas e variadas atividades da pesquisa. Às vezes, quando se considerava relevante, os grupos eram divididos por sexo, assim como por classe social ou origem étnica. Três diferentes pesquisadores - duas mulheres e um homem - revezavam-se nos grupos, e, segundo o autor, o objetivo desse design "não era tanto o de 'controlar' a influência de diferentes agrupamentos ou diferentes estilos de entrevista, e sim tornar possível estudar a fala das crianças em uma variedade de diferentes contextos interpessoais" (BUCKINGHAM, 1993, p. 36). Um exemplo é o relato de um diálogo em que um grupo só de meninas assistiu um desenho animado, e uma delas perguntou ao pesquisador por que não estava entrevistando meninos, já que, na opinião dela, esses programas eram mais "para meninos, porque tem mais meninos e homens neles" (BUCKINGHAM, 1993, p. 54). As outras meninas concordaram, comentando que por isso gostavam do desenho She-Ra, que mostrava uma super-heroína, e a partir daí desenvolveram toda uma longa conversa criticando a atitude dos meninos no parque e nos jogos, onde eles "tomavam conta da bola", não as deixando brincar. O pesquisador identificou que a crítica feita por elas aos desenhos animados era parte de uma preocupaçáo bem mais ampla das meninas, e que na discussão elas "estavam construindo ativamente uma solidariedade de grupo apoiada em linhas de gênero, de uma forma que seria obviamente mais arriscada em um grupo de discussão misto" (BUCKINGHAM, 1993, p. 55). A conclusão dos pesquisadores foi a de que as crianças percebiam aqueles desenhos animados como sendo fortemente determinados por marcas de gênero. Ao mesmo tempo, durante as discussôes era possível observar alguma incerteza e flexibilidade nas posiçóes de gênero assumidas pelas crianças: 
As identidades de gênero das crianças não eram unitárias ou fixas, mas, ao contrário, estabelecidas e negociadas no decorrer da discussão. As crianças definiam-se e eram definidas pelos outros de diferentes maneiras, dependendo dos objetivos. A identidade de gênero, poderíamos dizer, era conquistada, mais do que simplesmente dada. (BUCKINGHAM, 1993, p. 58).

Buckingham (1993) defende a necessidade de análises complexas da recepção infantil e critica o determinismo textual, observando, por exemplo, que seria simplista dizer que o sexismo nos programas para crianças era a principal causa de atitudes sexistas entre elas. Ao mesmo tempo, seria igualmente redutor sugerir que a recepção das crianças seja uma função direta de sua condição social: "Nem o sentido do texto, nem as posições sociais das crianças são inteiramente dadas: se por um lado existem definitivamente limitaçóes a ambas, elas são estabelecidas e negociadas ao mesmo tempo por meio da conversa" (BUCKINGHAM, 1993, p. 59).

$\mathrm{O}$ autor relata que quando um dos meninos adotava uma determinada posição particular - por exemplo, uma exagerada identificaçáo com estereótipos de masculinidade, como a predileção por notícias de violência e guerra - isso não necessariamente deveria ser visto como um reflexo de seu "verdadeiro eu", nem, por outro lado, como evidência de um condicionamento social todo-poderoso. É preciso reconhecer a existência de uma margem considerável de escolha e criatividade ligadas ao contexto interpessoal da conversa. Ao mesmo tempo, ele alerta quanto ao risco de se exagerar o grau de poder ou liberdade das crianças-espectadoras, observando que, "se precisamos reconhecer o que os/as leitores/as trazem ao texto, precisamos também levar em conta aquilo que eles/as encontram lá” (BUCKINGHAM, 1993, p. 59). Ou seja, o foco nas pesquisas de recepção e na agência semiótica das crianças não invalida a importância das análises críticas às representaçôes - de gênero, no caso - presentes nos textos audiovisuais em circulação nas mídias.

Outros aspectos cotidianos de gênero foram problematizados nas análises, como, por exemplo, as estratégias de poder dentro das famílias em relação ao controle da programação de TV, e as avaliaçôes quanto aos programas "apropriados para meninos e para meninas". Neste caso, a pesquisa empírica mostrou grandes diferenças, em alguns grupos específicos, entre as avaliaçôes dos meninos e as das meninas. Para o autor, porém, "isto náo reflete necessariamente que os meninos e as meninas se relacionem de formas diferentes com a TV, e sim aquilo que foi possível a eles/as dizer naqueles contextos específicos e como eles/as suspeitavam que os outros respondessem a isso" (BUCKINGHAM, 1993, p. 216). 
De modo geral, pode-se dizer assim que a perspectiva de Buckingham (1991, 1993) em relação a gênero, em suas extensivas pesquisas empíricas com crianças e mídias, alia-se às epistemologias feministas que enfatizam a importância das negociações e conflitos, por meio dos quais as crianças participam coletivamente, a partir de suas práticas sociais, da construção de gênero (THORNE, 1993).

Nessa mesma direção seguiram as pesquisas de Joseph Tobin (2000) sobre a conversa das crianças a partir de filmes e programas de televisão, com especial atenção aos temas ligados à classe, raça e gênero. Partindo da concepção de gênero como performance desenvolvida por Judith Butler, ele interpreta o que as crianças dizem como sendo formas de desempenhar versôes convincentes de gênero (assim como de etnicidade e pertencimento local) para si mesmas, para os colegas e para o/a pesquisador/a. Suas análises dão grande atenção à dinâmica de interação entre as crianças, comparando grupos do mesmo sexo e grupos mistos.

$\mathrm{Na}$ pesquisa que realizou com crianças em escolas do Havaí, o autor percebeu uma tendência de as meninas serem mais espontâneas e participativas quando estavam somente entre meninas, ao contrário dos meninos, que mantiveram mais ou menos o mesmo padrão de apresentação tanto em grupos só de meninos como em grupos mistos; e sugeriu que talvez isso ocorresse porque aqueles meninos náo conhecessem outros modos de performar masculinidade. A tese de Tobin (2000, p. 33) é a de que "a conversa sobre filmes e televisão é um lugar-chave para as crianças ensaiarem e desempenharem papeis de gênero, e que os roteiros disponíveis para essas performances são restritivos e constrangedores tanto para as meninas como para os meninos, e talvez ainda mais para estes". O autor adverte, seguindo a perspectiva de Barrie Thorne (1993) e de outros/as pesquisadores/as, para que nas análises do material de campo náo sejam exageradas as diferenças entre meninos e meninas, buscando-se não focar em comportamentos extremos e sim na relativa continuidade existente entre identidades e performances de gênero entre meninos e meninas de um mesmo grupo.

O trabalho de Tobin (2000) é potencialmente muito inspirador para as análises da fala e das demais expressóes das crianças sobre suas experiências com as mídias. Ele propóe olhar de modo oblíquo para as transcriçóes das conversas, como fariam detetives ou psicanalistas, em busca de detalhes estranhos, que fujam ao previsível, por ser ali que, às vezes, se poderá encontrar os sentidos mais importantes de um discurso. Um exemplo dessa intuição analítica é a sugestão de que se analise os diálogos das crianças de modo contínuo e não como fragmentos descontextualizados:

Minha análise se baseia no conceito de performance nos dois sentidos do termo: os comentários das crianças podem ser lidos de modo mais útil como tentativas de performance de gênero 
do que como marcadores de identidades de gênero preexistentes trazidas à conversação, e as transcriçóes se tornam mais significativas quando abordadas como uma peça teatral, mais do que como uma coleçáo de afirmaçóes independentes. (TOBIN, 2000, p. 35).

Explorando as possibilidades analíticas desse olhar psicanalítico-detetivesco, apoiado também no dialogismo bakhtiniano, Tobin (2000, p. 49) examina temas como, por exemplo, a vulnerabilidade de alguns meninos, mal-disfarçada por trás de um discurso machista - "Gosto de sangue, gosto de violência, odeio filmes de amor e de animais" -, e a necessidade de não confundir as performances públicas femininas e masculinas ao assistir um filme com o que aquelas pessoas de fato pensaram e sentiram. A cuidadosa análise dos aspectos de gênero da recepçáo infantil feita pelo pesquisador deixa evidente a importância da atenção ao contexto social e cultural de interação em ação nas situaçôes de pesquisa, e especialmente aos seus detalhes imprevisíveis e potencialmente perturbadores das concepçóes preconcebidas que possamos levar conosco ao cenário da investigação.

Apontamos acima alguns exemplos das preocupaçóes com gênero que fazem parte da abordagem teórico-metodológica na qual as pesquisas de nosso grupo vieram se apoiando. Ainda que em sua maior parte estas pesquisas não tenham dado proeminência à categoria gênero, o tema estava, por assim dizer, nas entrelinhas e notas de rodapé dos trabalhos. A seguir, indicaremos algumas das reflexôes ligadas a gênero em algumas pesquisas do grupo, neste exercício de explicitar e trazer para o primeiro plano anotaçôes eventualmente marginais nesse conjunto de pesquisas sobre a experiência cotidiana das crianças com as mídias.

\section{Crianças conversando gênero ${ }^{4}$ nas pesquisas do grupo}

A atenção ao pano de fundo sociocultural em que se dá a recepção é um pressuposto importante da pesquisa com crianças sobre sua experiência com as mídias, que é mergulhada nas rotinas, rituais e instituiçôes cotidianas. Para ilustrar essa busca de contextualizar a recepção, citamos a pesquisa sobre imaginário infantil, consumo de mídia e práticas culturais que realizamos com 90 crianças de 7 a 8 anos de idade em quatro diferentes lugares sociais da cidade de Florianópolis (GIRARDELLO, 2001): a escola da favela mais pobre, uma escola tradicional de elite, a escola de um vilarejo de pescadores e a maior escola pública do estado (com clientela heterogênea). O foco da pesquisa era conhecer melhor a presença e o papel das mídias no imaginário e no cotidiano das crianças e, como não poderia deixar de ser, muitos aspectos relativos a gênero emergiram das discussóes. 
Uma das questôes geradoras que propusemos aos grupos mistos de discussão era: "Quem as crianças que vocês conhecem mais admiram?", tema que em alguns casos gerou diálogos polarizados em relação a gênero. Em uma das escolas, por exemplo, enquanto as meninas falavam da admiração que suas amigas em geral tinham pela cantora Sandy, na época um ídolo teen, os meninos faziam cara de náusea, dizendo: "ela é feia e chata". Perguntamos a eles, entâo, o que achavam, quando viam meninas falando sobre a cantora:

Menino: A gente sai correndo, porque é um saco.

Menino: Dá vontade de vomitar.

Pesquisadoras: Por quê?

Menino: Coisa de guria.

Menino: É.

Pesquisadoras: Vocês não assistem à novelinha da Sandy?

Menino: Não!

Menino: Eu pego e desligo a TV na hora! (GIRARDELLO, 2001, p. 96).

E a discussão foi além, configurando-se como um exemplo das "guerras de gênero" de que fala Tobin (2000), em que para muitos meninos em situaçóes de grupo, a busca de afinar-se à normatividade de gênero envolve não apenas demonstrar interesses "masculinos", mas também menosprezar as meninas e seus interesses. As meninas, parecendo provocadas por aquela explosão, assumiram uma postura também crítica, só que em relação ao parceiro e irmão de Sandy, depois que fizemos referência a ela na continuidade da conversa:

Pesquisadoras: Mas tem o Júnior também, vocês não acham graça [nele]?

Menina 1: Eu não, eu acho o Júnior muito bichinha.

Menina 2: [Concorda]. Canta música de mulher.

Pesquisadoras: Como é que é música de mulher?

Menina 2: Ele fica cantando as músicas da Sandy. Ele canta música de mulher, eu náo gosto dele.

Menina 1: Eu não gosto dele porque ele tá sempre usando brinco dos dois lados. Ele tá sempre usando colar, e eu acho ele muito bichinha. (GIRARDELLO, 2001, p. 96).

A fala destas crianças de sete anos, além de revelar as dinâmicas de poder presentes no diálogo social e reproduzidas pelas crianças, denota como se dá precocemente a incorporaçáo do discurso preconceituoso dos adultos, e o quanto é 
justificada a formação de educadores/as para a mediação no sentido de uma educação não sexista e não homofóbica.

A conversa das crianças sobre o que encontram nas mídias mostra-se um cenário dos mais importantes para essa mediação, uma vez que ali se percebe também negociação, tensão e resistência aos estereótipos. É o que evidenciaram algumas das pesquisas de nosso grupo, como a de Garzel (2004) sobre o modo como crianças de 10 e 11 anos percebiam o jornalismo, em diálogos como este:

Pesquisadora: [...] É porque assim, ó, naquela outra pergunta que eu perguntei o que... se vocês pudessem escolher o que ia ter no jornal de notícias, assim, a maioria dos meninos falou que queria notícias de violência, de tráfico de drogas...aí eu fiquei na dúvida, porque quase nenhuma menina escreveu isso. Por que tu achas que os meninos escreveram isso?

Menino 1: Porque eles gostam de violência, né? A maioria.

Menino 2: Eu não gosto!

Menino 3: Ele são mais bruscos, né? Eles são mais brutos!. O Marcos, né.

Menino 2: Não, não vamos citar nomes...

Menino 4: Mas daí é porque decerto também eles acham assim, sabe? Mais interessante chegar e dizer assim, olha só, eu mando no pedaço, daí beleza. Sou mais forte do que tu, né...Eu não faço assim.

Menino 2: Nem eu!

Pesquisadora: E tu acha que é real que eles se interessam por isso, ou eles só querem fazer essa pose de machão?

Menino 4: É mais essa pose de machão mesmo assim... [...].

Menino 2: Mais, é isso mesmo. (GARZEL, 2004, p. 80-81).

Segundo a pesquisadora, esses meninos estavam reconhecendo a existência de um discurso machista, "que interfere nas atitudes e nas falas de algumas pessoas", e também o quanto muitas vezes os meninos a quem se referem estavam apenas interpretando um papel (GARZEL, 2004, p .80-81). Um processo semelhante de "tensão entre naturalização e contestação de estereótipos" foi verificado por outra pesquisadora do grupo, na conversa de crianças de 6 e 7 anos sobre as representaçóes de gênero em sites para crianças na internet, como se observa no seguinte diálogo:

Pesquisadora 1: O que os homens, meninos, meninas e mulheres desse site fazem?

Paulo: Eles tão no ônibus da escola e tinha um lá atrás enchendo o saco. 
Pesquisadora 1: Quem tava enchendo o saco?

Paulo: O Pitiburro

Pesquisadora 2: E o Pitiburro é um cachorro menino ou menina?

Paulo e Carla: É macho.

Pesquisadora 1: Por que ele parece ser macho?

Artur: Ah, dá pra perceber.

Pesquisadora 1: Como?

Carla: Porque ele só fica fazendo bobeira, ele não fica bem comportado como as meninas.

Pesquisadora 2: E vocês conhecem meninos que nem o Pitiburro?

Carla: Eu conheço! Dois da minha sala. [...]

Pesquisadora 1: E vocês acham que todos os meninos são desse jeito?

Carla: Não.

Pesquisadora 2: E tem meninas que săo assim?

Artur: Tem. (DIONÍSIO, 2006, p. 6).

A partir da relativa complexidade de discussôes como essa, Dionísio (2006) defende a importância de uma maior participação das crianças na criação de websites para o público infantil, já que o exame feito por ela mostrou que "alguns dos sites mais acessados pelas crianças brasileiras continuam trabalhando dentro de uma lógica binária, que opóe um modelo de menino - bagunceiro e ativo - a um modelo de menina - frequentemente imersa em um mar cor-de-rosa" (DIONÍSIO, 2006, p. 7).

No contexto da mesma pesquisa, propôs-se que as crianças refletissem sobre a questão do endereçamento dos sites comerciais, em termos de gênero. Perguntou-se às crianças da primeira série, sobre o site da boneca Barbie (que se apresenta como de "Atividades e jogos para Garotas On Line!"): "Vocês acham que esse site é pra menino, pra menina ou para os dois?”.

Pesquisadora 1: E o site da Barbie?

Maria: É pra menina.

Artur: É para os dois.

Pesquisadora 2: Por que será que o Artur acha que o site da Barbie é de menino e de menina e a Maria acha que é só de menina?

Maria: Porque [no site] tem mais menina do que menino.

Pesquisadora 1: Tem mais alguma coisa no site que faz ele ficar com cara de site de menina? 
Maria: Não.

Artur: Pra mim é porque não faz mal se o menino estiver brincando com uma coisa de menina.

Pesquisadora 1: Tu gostarias de brincar no site da Barbie, Artur?

Artur: De vez em quando sim. Só quando não tiver ninguém olhando.

Pesquisadora 1 : Por que não pode ter ninguém olhando? Artur: Ah, porque senão todo mundo vai me chamar de bicha. (DIONÍSIO, 2006, p. 8).

Diante do complexo e, por vezes, angustiante exercício de performance identitária e constituição subjetiva evidenciado em diálogos como esse, a pesquisadora percebeu como sendo ainda mais grave o reforço à normatividade dualista expressa, por exemplo, nos adjetivos associados a personagens meninas e a personagens meninos nos sites comerciais mais acessados pelas crianças. Ali, uma menina é "estudiosa", a outra é "humilde", outra "apaixonada", "chorona”, "descontraída”, "alegre" ou "ciumenta”. Os personagens meninos, por sua vez, são em geral alguém "destemido", “corajoso", "líder", "desleixado", "burrinho" ou que "não gosta muito de estudar" (DIONÍSIO, 2006, p. 4).

$\mathrm{Na}$ época em que o trabalho foi realizado, entre 2005 e 2006, Dionísio (2006) fez uma comparação com as críticas aos estereótipos na literatura infantil produzidas na década de 1970 no Brasil, e concluiu que algumas representaçóes de feminino e masculino, embora ainda presentes, já não eram tão recorrentes, como o confinamento da mulher ao espaço doméstico e matrimonial e a associação dos meninos à força e à agilidade. Outras, porém, persistiam, como "a imagem da princesa como modelo de beleza, junto com o 'ethos da telenovela' em que estão inseridas outras personagens femininas, frequentemente caracterizadas como belas e virtuosas" (DIONÍSIO, 2006, p. 7). A autora concluiu que "sem conhecer as crianças reais, suas práticas culturais, seus contextos sociais, os autores de materiais infantis contribuem para a naturalização de estereótipos [...] e os modelos normativos também influenciam a construção das identidades de gênero desses usuários" (DIONÍSIO, 2006, p. 8).

Outra pesquisa realizada no grupo teve por foco investigar a presença do imaginário midiático na cultura lúdica das crianças na educação infantil, manifestada especialmente em suas brincadeiras no pátio (MUNARIM, 2007). A participação infantil foi uma importante preocupação metodológica, tendo sido entregues câmeras fotográficas às crianças para que registrassem as brincadeiras dos/as colegas. A pesquisadora dedicou uma seçáo do trabalho às questóes de gênero que emergiram das 
brincadeiras e conversas das crianças durante a pesquisa de campo. Seu relato de modo geral confirma observaçóes de sociólogos estudiosos da infância como Gilles Brougére e Gisela Wajskop, que caracterizam as brincadeiras de faz de conta ligadas ao cotidiano como sendo preferência das meninas, e brincadeiras mais "ativas" e heroicas, com simulaçóes de lutas, corridas e saltos, sendo mais relacionadas aos meninos. Ela observou, porém, alguns casos que fugiam a esse padrão, como o de dois meninos que "estavam brincando de papai e filhinho e, pelo jeito, eram pescadores, pois em suas falas ouvi 'foi o papai que pescou'” (MUNARIM, 2007, p. 154). Como no contexto familiar daquelas crianças havia muitos pescadores, a autora comenta que, brincando, os meninos se apropriavam de açóes possivelmente presenciadas no ambiente familiar, ou seja, também brincavam de casinha.

A importância do imaginário social e cultural que cerca as crianças é evidentemente vital para os conteúdos das brincadeiras, o que torna crucial a atenção dos adultos para as imagens que povoam esse universo. A época em que aquela pesquisa foi realizada, durante a Copa do Mundo de 2006, fazia com que os times de futebol masculinos dominassem o discurso televisivo, e tanto os meninos como as meninas mostravam-se muito empolgados com o tema. Isso fazia aflorar alguns conflitos específicos, como o relatado a seguir pela autora, utilizando-se dos pseudônimos escolhidos pelas próprias crianças:

Maria Júlia disse ao Homem Aranha que queria jogar, ele disse que não, que estava escrito que meninas nấo podem jogar, só podem ser torcida. Maria Júlia náo gostou e perguntou onde estava escrito isso, ele fala que no campo, ela pergunta 'onde' novamente, ele diz que é faz de conta e vai até a trave: "Aqui ó, aqui que tá escrito: meninas não jogam, só meninos! As meninas têm que ficar na torcida!”. Maria Júlia parece se sentir provocada e afirma energicamente que é o contrário (MUNARIM, 2007, p. 153).

Pode-se imaginar a dificuldade da menina para fazer valer seus argumentos, contra toda uma torrente de imagens, inclusive midiáticas, mostrando o futebol como se fosse um esporte exclusivamente masculino. A pesquisadora comenta também as brincadeiras ligadas a magia, lutas e aventuras que presenciou em instituiçóes de educaçáo infantil, onde foram constantes personagens como piratas, cavaleiros e superheróis televisivos, usando espadas, armas e armadilhas. Nestes cenários, foram observados aspectos de gênero importantes, como no exemplo abaixo, relatado pela autora: 
[A menina] Luiza e mais uma colega brincavam de luta, com dois galhos na mão.

Desafiavam-se como se estivessem com espadas em punho. [...] Luiza me chama atenção, passando por mim e contando que ela e sua amiga estáo brincando de luta. "Mas é luta de brincadeira, porque a gente é menina, os meninos não". Pergunto a ela por quê, ela responde: "é que as meninas brincam de luta de brincadeira, os meninos é luta de verdade!” (MUNARIM, 2007, p. 160).

Para a pesquisadora, a distinção feita pela menina pode ser melhor compreendida naquele contexto, em que as lutas encenadas pelos meninos frequentemente acabavam em choro. E cita, apoiando-se em autores como Gilles Brougère, o quanto essa diferença entre as brincadeiras dos meninos e das meninas é reforçada pelos programas televisivos e todo o marketing que os envolve, de brinquedos a biscoitos.

Outra pesquisa em que as próprias crianças colocaram o tema gênero na pauta das conversas nos grupos focais foi a dissertação de Rosane Kreuch (2008), sobre a participação das crianças nos websites das escolas municipais da cidade de Florianópolis. Nesse trabalho, as crianças - com idade entre 9 e 11 anos - examinaram em conjunto os limites do site institucional de sua escola e as possibilidades de sua participação em sua produção. A partir do tema gerador "Se esse site fosse nosso...", proposto pela pesquisadora, dois temas surgiram espontaneamente em todos os cinco grupos focais em que as crianças se dividiram: o desejo de que houvesse mais jogos no site e a insatisfação com a abordagem de gênero utilizada. Em um dos grupos, por exemplo, um terço das crianças (dois meninos e uma menina) disseram achar o site "muito feminino", referindo-se a ícones de flores e gatinhos usados como enfeites pela professora responsável pelo site. Como relata a autora, as crianças consideraram tais elementos "são reprováveis num site que deve apresentar um grupo heterogêneo" (KREUCH, 2008, p. 185). Um dos meninos chegou a propor que o site tivesse um endereçamento claramente dividido por gênero, evidenciando desconforto com uma estética da qual se sentia excluído:

Lobinho (M): Não entro muito [no site]. Não gosto muito. Podia ter, no começo, lá: [na página inicial do site] modo feminino e modo masculino. Ou podia ter tudo misturado. Eu não gosto de entrar no site.

Vida (M): Vê, é tudo muito rosinha (apontando os ursinhos que pulam na tela do micro enquanto ele clica nos links)

Lobinho (M): Aqui também. Chato isso. É tudo muito feminino. (KREUCH, 2008, p. 185). 
A análise da pesquisadora é cautelosa, apontando para o quanto as falas das crianças podem ser evidências de uma concepção discriminatória de gênero produzida culturalmente, e lembrando que a razáo do desconforto - sentido também por uma menina, neste exemplo - não são as diferenças de gênero em si, mas a desigualdade e a exclusão causada por estereótipos em relação a gênero: "Assim, ao invés de reforçar estereótipos sobre masculinidade e feminilidade, a escola poderia contribuir para a construção de identidades menos discriminatórias e mais livres" (KREUCH, 2008, p. 160).

O trabalho de Kreuch (2008) é interessante também por garantir espaço a um grupo focal de estudantes surdos, permitindo a manifestação, no contexto da pesquisa, de crianças cujo desejo de participação e visibilidade no site da escola não estavam sendo levados em conta. Em suas conclusóes, o trabalho reafirma "a importância e a urgência da mídia-educação como busca de garantir os direitos de provisão, produção e participação das crianças nas mídias" (KREUCH, 2008, p. 232), especialmente a partir das novas possibilidades participativas oferecidas pela internet. Nesse contexto, fica destacado o potencial da participação autoral e criadora das crianças na cultura das mídias, também como oportunidade de maior riqueza e heterogeneidade nas formas de representação relativas a gênero.

Outra pesquisa realizada no grupo em que a dimensão de gênero fica visível na fala das crianças sobre televisão é a dissertação de Patrícia Bieging (2011), cujo foco era a relação entre estereótipos como "populares", "perdedores", "nerds", "patricinhas" e "fracassados", presentes em programas de televisão, e o discurso cotidiano das crianças. Em um estudo de recepção de cunho etnográfico, a autora acompanhou discussôes com grupos mistos de crianças de 9 a 12 anos de idade, que incluíram a audiência a dois audiovisuais cujo tema era a crítica à discriminação entre crianças a partir de rótulos como populares e perdedores (um episódio da série Hannah Montana, dos estúdios Disney, e o curta de animação brasileiro Zica e os Camaleóes, dirigido por Ari Nicolosi Mota, ambos produzidos em 2009). A autora verificou distinçóes de gênero nos sentidos que as crianças de ambos os sexos atribuíam aos estereótipos, como neste exemplo:

Poderíamos arriscar dizer que, na visão das crianças, meninas 'populares' seriam as que se vestem com roupas e acessórios da moda e meninos 'populares' seriam os que possuem boa habilidade com os esportes, ou até mesmo crianças que se destacam através de outras atividades dentro do contexto social a que pertencem. (BIEGING, 2011, p. 116). 
A referência ao bullying emergiu com força nas conversas das crianças, ainda que a discussão do tema não estivesse inicialmente prevista na pesquisa. Em vários momentos, a fala das crianças sobre bullying evidenciou tensóes ligadas a aspectos de gênero, como nos exemplos abaixo:

Jade: $\mathrm{O}$ meu amigo, ele tem mania de ficar chamando os outros de baleia, de preta, de idiota. [...] Ele é assim, encostou o dedo na mulher, ele bate. Ele já bateu num monte de menina, não só em mim. Tem outro amigo meu que também é vítima de bullying. (BIEGING, 2011, p. 141).

Bela: Eu sempre me ferro porque eu defendo as minhas amigas. Se alguém xinga elas, eu sempre vou lá e falo alguma coisa. A menina que foi xingada de baleia náo queria falar nada pra diretora. Aí eu expliquei que ela tinha que falar, pois ela podia ficar em depressão com isso. Porque ela já ficou em depressáo uma vez. Uma vez a gente tava brincando e começaram a chamar ela de lésbica, mas daí eu fui lá e briguei com os guris. Daí eles começaram a me chamar de lésbica. Eu falei para eles que eu não fazia nada pra eles, então eles não podiam fazer nada pra mim. (BIEGING, 2011, p.147).

Além da expressividade dessas falas para a compreensão das relaçóes de gênero entre crianças e para a reflexão sobre os modos como os/as educadores/as podem agir sobre eles, a pesquisa de Bieging (2011) deixa claro o valor dos estudos de recepção nas abordagens ao cotidiano, à subjetividade e às interaçóes infantis, considerando que a partir dos vídeos assistidos as crianças se colocaram abertamente sobre sua convivência com os/as colegas e revelaram conflitos que talvez de outra forma não fossem visibilizados. Outro dado importante é a evidência de que as crianças passaram a pensar e falar mais sobre bullying a partir de projetos educativos de que vinham participando nas escolas municipais, como se percebe neste diálogo com dois meninos de 12 anos:

Black: Sem perceber eu praticava bullying. Eu chamava uma menina de jabulane. E ela corria atrás da gente [ aponta para Leike]. Era tudo brincadeira.

Leike: Jabulane, a bola da copa, sabe?

Black: Mas eu não sabia que ela se sentia mal, nada...ela não falava, ela não demonstrava isso. Daí eu ouvi ela falar que eu praticava bullying. [...] eu não sabia que apelido também era bullying.

Pesquisadora: E o que você achava que era bullying?

Black: Bullying eu achava que era o pai organizar brigas para os filhos. Não sabia que apelido também era. (BIEGING, 2011, p. 143). 
As crianças fizeram muitas referências espontâneas ao tema bullying em suas conversas. Se por um lado mostravam diferentes níveis de compreensão da linha divisória entre brincadeira e violência simbólica - uma fronteira controversa também entre muitos adultos - as crianças deixavam claro que a incorporação daquela nova palavra ao seu vocabulário produzia novas possibilidades de reflexão e configuração de suas relaçóes sociais e constituição subjetiva. Esse fato pode contribuir também para a afirmação da importância dos projetos educativos ligados a gênero e diversidade na escola.

\section{Considerações finais}

Procuramos neste trabalho explicitar alguns pressupostos ligados a gênero que estavam presentes no horizonte teórico-metodológico de um conjunto de pesquisas com crianças sobre sua vida com as mídias, realizadas ao longo de uma década em nosso grupo. Avaliamos que, embora tais pressupostos tenham em geral se limitado às entrelinhas e aos rodapés dos relatórios das pesquisas, já que o foco dos estudos quase nunca era gênero, eles se manifestam em uma relativa coerência nas análises das falas das crianças feitas pelas autoras. Ao reler cuidadosamente esse conjunto de pesquisas, encontramos diversas referências ao tema gênero, e pinçamos delas as transcriçôes de alguns diálogos em que aparecem tensōes e negociaçóes ligadas a expectativas e preconceitos em relaçáo ao que são ou devem ser meninos e meninas, homens e mulheres. Isso mostra que muitos trabalhos de pesquisa atentos à complexidade das interaçôes entre as crianças acabam evidenciando a intensidade da dimensão gênero, que se revela mesmo quando não está sendo intencionalmente procurada.

No âmbito da mídia-educação, em que nosso grupo se insere, é recorrente a defesa dos "3 P" na relação das crianças com as mídias: a Provisão (o acesso a um repertório de qualidade); a Proteção (quanto a processos e conteúdos potencialmente inadequados); e a Participação na criaçáo midiática. A leitura das pesquisas acima ajuda a valorizar essas três dimensôes também em relação a gênero. $O$ potencial da participação autoral e criadora das crianças em todas as dimensôes da cultura das mídias configura-se como oportunidade de maior riqueza e heterogeneidade nas formas de representaçáo relativas a gênero. Ao mesmo tempo, a crítica aos modelos dualistas e estereótipos permanece sendo muito importante: por mais que se multipliquem hoje no Brasil as iniciativas de mostrar às crianças imagens e narrativas atentas à diversidade e à complexidade das relaçôes humanas, as próprias crianças identificam e muitas vezes chegam a mostrar desconforto diante de personagens e situaçôes presentes na cultura das mídias que lhes parecem constrangedoramente sexistas ou de um binarismo confinante. Em vários momentos, ficou claro o quanto os jogos de poder e performance 
entre as crianças, atravessados por dimensões de gênero, podem gerar desigualdade e exclusão.

As palavras ditas por crianças nos contextos examinados, além de revelar as dinâmicas de poder que marcam o diálogo social e cultural do qual as crianças fazem parte, mostram reflexos, apropriaçóes e recriações do discurso preconceituoso dos adultos. Isso comprova o quanto são justificados e importantes os projetos de formação de profissionais para uma educação não sexista e não homofóbica. A conversa das crianças sobre suas experiências com as mídias, por fim, confirma-se como uma instância valiosa para a educação e a pesquisa, já que é um cenário de constituição subjetiva e produção social de sentidos, onde se dá a tensão entre naturalização e resistência aos estereótipos, inclusive de gênero, que empobrecem a experiência humana.

\section{Notas}

${ }^{1} \mathrm{O}$ Grupo Infância, Comunicação, Cultura e Arte (NICA), CNPq/UFSC, atualmente coordenado pela autora e por Monica Fantin.

${ }^{2}$ Observe-se, por exemplo, que, são raríssimos os trabalhos apresentados no GT Educação $e$ Comunicação da ANPEd que abordam os temas gênero e sexualidade. Esta pequena presença da temática nas pesquisas em Educação, e inclusive no GT 16, vem sendo evidenciada por Márcia Ondina Vieira Ferreira e colegas (FERREIRA; SANTOS, 2014).

${ }^{3}$ Esta e as demais traduções de obras originalmente em inglês citadas neste artigo são nossas.

${ }^{4}$ Referência à ideia do gênero como performance e construção social, presente por exemplo no título do livro de Barrie Thorne (1993) Gender Play: girls and boys in schoole no do Seminário Internacional Fazendo Gênero, promovido pela Universidade Federal de Santa Catarina (UFSC).

\section{REFERÊNCIAS}

BIEGING, Patrícia. Da busca da popularidade às práticas de bullying: crianças e produção de sentidos a partir de artefatos midiáticos. 2011.192 p. Dissertação (Mestrado em Educação) - Universidade Federal de Santa Catarina, Florianópolis, 2011.

BUCKINGHAM, David. What are Words Worth? interpreting children's talk about television. Cultural Studies, v. 5, n. 2, p. 228-245, 1991. 
BUCKINGHAM, David. Children talking television: the making of television literacy. London: The Falmer Press, 1993.

DIONÍSIO, Ana Carolina. O imaginário infantil e as mídias: um estudo das representaçóes de gênero em websites de entretenimento para crianças. 2005. Relatório (Iniciação Científica) - Curso de Jornalismo, Universidade Federal de Santa Catarina, Florianópolis, 2005.

FERREIRA, Márcia Ondina Vieira; SANTOS, Luciano Pereira dos. Diversidade sexual e docência na produção do Grupo de Trabalho 23 da ANPEd (2004/2011). Revista de Educação PUC-Campinas, Campinas, SP, v. 19, n. 3, p. 195-204, set./dez. 2014. Disponível em: <http://periodicos.puccampinas.edu.br/seer/index.php/reveducacao/article/view/2853>.

GARZEL, Cláudia. Jornalismo para crianças: um estudo sobre práticas culturais e consumo de mídia junto a crianças de 10 e 11 anos em Florianópolis. 2004. Monografia (Graduação em Jornalismo) - Universidade Federal de Santa Catarina, Florianópolis, 2004.

GIRARDELLO, Gilka. O Imaginário Infantil e as Mídias: um estudo de recepção junto a crianças de primeira série em Florianópolis. Florianópolis, SC:

FUNPESQUISA; UFSC, 2001. (Relatório Final).

HODGE, Bob; TRIPP, David. Children and television: a semiotic approach. Cambridge: Polity Press, 1986.

KREUCH, Rosane Maria. A participação das crianças nos websites das escolas municipais de Florianópolis. 2008. Dissertação (Mestrado em Educação) Universidade Federal de Santa Catarina, Florianópolis, 2008.

MUNARIM, Iracema. Brincando na Escola: o imaginário midiático na cultura de movimento das crianças. 2007. Dissertação (Mestrado em Educação) - Universidade Federal de Santa Catarina, Florianópolis, 2007.

THORNE, Barrie. Gender play: girls and boys in school. New Brunswick: Rutgers University Press, 1993.

TOBIN, Joseph. Good guys don't wear hats: children's talk about the media. New York: Teachers College, Columbia University, 2000. 


\section{Reading between the lines and footnotes: aspects of gender in research with children about media}

\begin{abstract}
This article examines Brazilian studies about media in the life of children, and emphasizes aspects of gender that were secondary in most of the research. Registers were found from field research - mainly statements from children - conducted between 2000 and 2010 in the context of a study group based at the Federal University of Santa Catarina. The works examined were based on cultural studies, Latin American reception studies and on contemporary childhood studies. Discussions about gender relations in research with children about media are part of this theoretical methodological framework, whose main aspects are synthesized in the work, mainly using concepts from Joseph Tobin and David Buckingham. The statements of the children registered and analyzed in the studies and selected in this work, led to the conclusions that while children often express and reproduce prejudice, they are also capable of identifying in the media culture problematic elements from the perspective of gender that provoke discomfort, inequality and exclusion; that the research situations in which the children discuss their experience with the media can be important spaces for negotiation and resistance; that criticism of dualistic and stereotyped representations of gender in the media continues to be very important in the 21 st century. This reaffirms the relevance of projects aimed at an inclusive, non-sexist and anti-homophobic education.
\end{abstract}

Keywords: Gender. Media. Children.
Leyendo entre líneas y pies de página: aspectos de género en investigaciones con niños sobre los medios de comunicación

\section{Resumen}

Este artículo examina un conjunto de investigaciones brasileńas sobre los medios de comunicación en la vida de los niños, colocando en primer plano aspectos de género que eran secundarios en la mayoría de los trabajos. En estas investigaciones se encuentran registros de campo - principalmente declaraciones de niños - realizadas entre los años 2000 y 2010 en el contexto de un grupo de la Universidad Federal de Santa Catarina. Estas investigaciones se basaron en estudios culturales, estudios de recepción latinoamericanos y estudios de la infancia contemporáneos. A partir de ese marco teórico-metodológico son parte de las discusiones las relaciones de género en la investigación con niños sobre los medios, cuyos principales aspectos se sintetizan en el trabajo, principalmente de Joseph Tobin y David Buckingham. Con base en los registros de los niños que fueron analizadas en las investigaciones y seleccionadas en el ámbito del presente trabajo, se concluye que, si muchas veces los niños exhiben y reproducen preconceptos, también son capaces de identificar en la cultura de los medios elementos problemáticos desde el punto de vista de género, que provocan malestar, desigualdad y exclusión; que las situaciones de investigación en las cuales los niños se manifiestan sobre su experiencia con los medios pueden ser un espacio importante de negociación y resistencia; que la crítica a las representaciones de género dualistas y estereotipadas en los medios permanecen siendo muy importantes en el siglo XXI. Basada en la discusión, se reafirma la importancia de realizar proyectos dirigidos a una educación inclusiva, no sexista y antihomofóbica.

Palabras claves: Género. Medios. Niños. 
Gilka Elvira Ponzi Girardello

E-mail: gilka@floripa.com.br

Recebido em: 30/12/2014 Aprovado em: 23/7/2015 